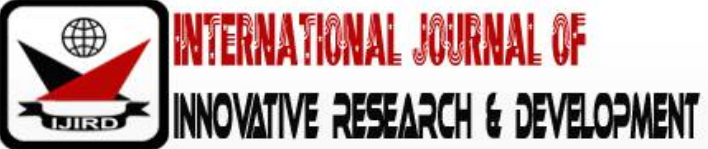

ISSN 2278-0211 (Online)

\section{Building Collapse in Nigeria: A Review and Delivery of the Future Using Big Data \& IOT}

\author{
Dr. Umbugala Muhammad Douglas \\ Senior Lecturer, Department of Building, Baze University, Abuja, Nigeria \\ Bala Muhammad \\ Dean, Department of Building, Baze University, Abuja, Nigeria
}

\begin{abstract}
:
Building collapse in Nigeria is alarming and indeed has become a subject of great concern. Many iconic structures now popping all over the developed countries from skyscrapers to bridges are mostly design and built now using BIM (building information modeling) transforming the Architects, Engineers, builders and the construction industry at large. Delivery the future requires moving with the changing dynamics, establishing objective approach using big Data and IOT (Internet of Things) to provide services at its utmost quality. Regulatory bodies and agency can share real time 24/7 data evaluation on its facilities visualizing instant inspection results with gap easily ascertained and timely addressed. This indeed will bring a huge difference on how we deliver services, hence keeping pace with the everchanging customer expectations and the evolving environmental concern. This research has attributed the incessant building collapsed to regulation, monitoring and enforcement inadequacy. This can be devastating if the right measures are not in place. The inflexibility can be enhanced using technology bringing ease of operational scaling and organization processes to optimize regulatory compliance, driven efficiency, automation and collaboration across board. This effort is a rare piece in this direction thus adding value to the research world.
\end{abstract}

Keywords: Building collapse, strategy shift, performance, excellence, sustainability

\section{Introduction}

Building collapse in Nigeria has being a recurring phenomenon; this indeed is alarming which demands urgency to eradicate or bring to the barest minimal the occurrence. The world had undergone transformation with the ever-changing technological innovations, corporate philosophy, and strategy on sustainable development; best practices continue to evolve in steps with the changing times. This unwavering focus has gained Singapore internationals recognition and envy, the country makes commitment to excellence and best practices as a compliment to continual support. Creating sustainable and optimal master piece in building productions in order to improve the quality of life for home owners, tenants these no doubt brought comfort and solace to its citizens [1].Analysis of the predominant practices in Nigeria had shown its weakness fundamentally focusing on capacity utilization rather than investing in research and development for its growth [2]. The severe shortage of diverse skills in Nigeria, in terms of availability, capacity and competency has negatively impacted on the development agenda of the country. The fundamental goal of this research is to evaluate relevant research with the view for a logical and better solution to halt these incessant failures in the nations. Sustainable development is key this era as health and comfort is to life, the world is facing largely energy and resource depletion and green building concept adopted by many countries as best and rational way forward [2].

The objective of this research is to highlights relevant reviews at the built environment cutting across the globe with more emphasis on the building failures, with clinical analysis on the causes. The benchmark result had shown an apparent poor delivery of services and finished building productions in Nigeria partly due to negligence, poor workmanship and proliferations of quacks in the industry as manifestation and ineffectiveness of the regulatory bodies in Nigeria. The driver of success in the new economy lies in the ability to adapt, collaborate, towards a smart society. Microsoft encoded its intellectual capital into software, while service professionals embedded on creation of products or value, therefore value and competitive edge by a firm has become the most critical success factor. Essentially creation of desire value entails creation of competitive strategy and services delivery that is safe, healthy and sustainable smart. Project delivery quality and the issues of building collapse have become alarming these indeed send signals of our collective failures in the industry.

\section{Building Collapse and the Colossal Effect across the Globe}

Recent years have seen alarming building collapse which indeed led to this research effort to mitigate generation gap and provide healthy shelters that is smart with heightened interest in big Data and IOT as the "knowledge and value refinery' this era. Research had acknowledged technology as resource for enhancing operation efficiency, reducing cost 
and improving decision making processes [3]. Sustainable buildings are outcome of design which focuses on technology thereby increasing the efficiency of resources' usage. Green buildings afford high level of environmental, economic and engineering performance. The world is going green the fate of Nigerian building industry is hazy. Reality facts demand not just the integration or collaboration of IOT and expect to find success rather monitoring performance and delivery of services is key for an end or minimal building failure across the globe. A thorough postmortem and analysis of the production and delivery process is necessary to ascertain gaps with the process intelligence.

Our pursuits of sustained quality services and sustainable building productions required proactive measures to ensure excellence and better dividends. Best practice organizations' focus on identifying the ever-changing job competence required to carry out the job role now and into the future. This includes monitoring critical parameters such as quality, time, customer satisfaction and employees' motivation to ensure continuous improvement and economic results [4]. This is the fundamental shift required of all, to refined expectations of the populace and the profession. This era had moved to a conceptual age where competence is only achieved by provision of proactive strategy that seek to guarantee expectations of all [5].

Research by [6] highlighted collapsed buildings across the globe, at Kaula Lumpur 1993 highland tower residential building collapsed, Sporthall in Halstenbek Germany in 1998 collapsed and to this also at Minneapolis USA, a stadium roof collapsed in 2010. Residential Building under construction collapsed in Sau Paulo Brazil in 2013. From theseit is obvious that building failure isa universal repugnant issue however the rate at which this occurs in Nigeria call for frantic intervention to arrest or salvage the situation. Nigeria in 1974, 1988, 2006, 2012 and 2013 at Rivers, Mokola Ibadan, Ondo, Ogun and Onitsha Anambra state respectively buildings collapsed and the cause of failures attributed to 'Structural', also in Nigeria 1980, and 2012 at Barnawa Kaduna and Awka Anambra respectively building collapsed and the cause of failures attributed to 'material defective'. In 2012 in Umauhia and Abia State, building Collapsed and the cause of failures is identified as 'non-adherence to regulations.'[7] Reported building collapsed at Taraba Nigeria, and in Helm France, with many casualties witnessed, according to [8], 199 people died in four Nigerian buildings collapsed between 2014 and 2016. However, in what seem to be the worst in this decade is that of Bangladesh [7] which has seen over 300 dead's, this indeed is a pathetic situation that requires swift action. Research by [9] carried out analysis on 47 collapsed between 2000-2010 and over 300 dead were recorded in Lagos, Abuja and Port Harcourt. The causes of failures identified as poor design, construction method, and unskilled workers. Analysis on 34 building collapsed between 2009-2019 [10] had recorded dead of 134 lives.

Highlights of tragedies in some African countries, collapsed in Uganda 2004 attributed to preference and usage of an unskilled worker to a trained builder, being penny wise and pound foolish. In Northern Rwandan a 4 storey building collapsed killing six, cause of failure 'in-adequate foundation', also building collapsed at Nairobi Kenya and Kampala Uganda 2016 the cause of failures attributed to 'counterfeiting materials'. The [11] reported building collapsed which saw 34 people dead, cause of failure attributed to 'overload' having more floors contrary to the approved design, this was two years after a church accommodation for famous preacher TB Joshua collapsed and over 100 people lost their lives. The greed for money had also seen a recalcitrant owner renovated a building marked in 2017 as distressed and unsafe without thorough engineering appraisal and integrity test. Two days after the collapsed Lagos state building control agency started demolishing about 100 buildings. Must the government wait till things go soar or worst before taking action? The casualties and dead could have been averted, if an earlier strategic action was carried out, the paper recorded 54 cases of building failure in 2017, just in Nigeria with the latest collapsed being the third recorded then in 2019. From the critical literature review the whole cases is wholly or partly more connected to regulations and enforcement, to illustrate this point a hypothetical case below is presented as further illumination, the state and height of decay in the industry.

\section{Approach and the Change in Narratives}

Construction of this proposed residential project commenced five (5) years ago i.e. 2015, the available approved documents for the proposed residential building were carefully studied. The available documents include; 'Architectural Working Drawings', 'Structural Details' and 'Mechanical\& Electrical Designs'. SAR and BOQ were not available. The study of the available documents was followed by critical observations on the existing structure.

Surprisingly, many discrepancies were observed between the contents in the approved documents and the real structure standing physical on the plot. For instance, the approved 'Architectural Working Drawings' revealed that the proposed project was initially intended to be a two-storey twin duplex blocks with a large children's playground and a sufficient car parking lot. However, the structure currently on the ground is by far different from the initial plan. Indeed, the structure now consists of five similar attached terrace units of apartments and one semi-detached unit; making a total of six units. In addition, the children's playground is completely missing. Where are the regulatory bodies the so-called NIA (Nigeria institute of Architects), and the NITP (Nigerian institute of town Planners), COREN (Council for registered engineers of Nigeria) and CORBON (Council for registered builders of Nigeria)?

Meanwhile, the changes evolved over the period under construction and possibly the several 'after thoughts' which clearly appeared in many parts of the structure coupled with poor workmanship which have clearly disfigured the structure in many respects. In fact, in addition to the physical differences between the approved building and the structure currently on the ground, there are quite an alarming number of structural defects in the structure. After several days of careful inspection of the structure the pronounced structural defects associated with the existing structure are hereby presented below. 


\subsection{Foundation Settlement}

Figure 1 presents large diagonal crack ripping across the ground floor walls of the left side of the structure. The diagonal crack has wider opening at the top and smaller gap towards the bottom right which is a clear indication that the foundation under the left side has entertained some amount of settlement (sinkage). Foundation settlement, particularly when it affects some parts of the foundation, leaving the other parts unaffected (known as uneven settlement) will normally depicts cracks of the nature seen in the Figure below.

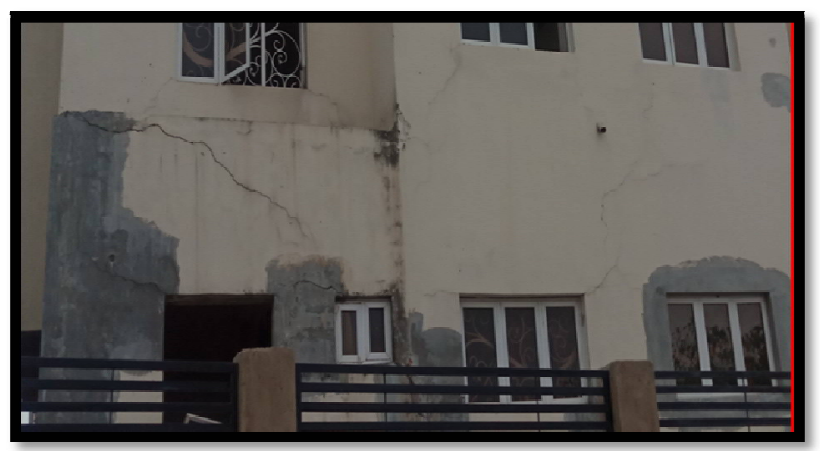

Figure 1: Diagonal Crack Resulting from

Foundation Settlement

Cracks caused by uneven settlements are usually progressive both in extent (length) and width. The rampant cement-mortar work patches (shown in the darker portions) displays further possible frantic efforts towards curtailing the consequence of the deteriorating condition of this part of the structure. In this respect, additional diagonal cracks could be sighted on the right-side portion of the structure.

Foundation settlements are purely structural problems and these usually pose serious threats to occupants as well as their belongings. Unless fully addressed immediately, these cracks will keep on increasing in length and width until partial or total collapse occurs.

\subsection{Soil Bearing Capacity}

Safe bearing capacity of soil is normally determined after a careful soil analysis. In other words, foundations are usually positioned on a soil stratum found to be of sufficient strength to disallow for settlement when the building is finally constructed. The incidence described in 'Section 3.1' invariably portrays the fact that the foundation is either positioned at a shallower point than recommended or the intended load at the recommended depth has been exceeded. Meanwhile, close inspection on the structure revealed possibilities of both recommendations being violated.

While some foundations were constructed at close to the ground surface levels, some walls were increased in thickness through cladding with pieces of blocks and in some cases with thick plaster. In addition, several suspended floors (decks) were cast on uneven platforms of formwork and the unevenness can only be hidden under false ceilings or taken care of through thick plaster.

Figure 2 below presents typical place where foundations were footed on loose soil at ground surface levels. The soil was found to be so soft that it can be removed using ordinary bare hand. This background doesn't look like a newly constructed structure.

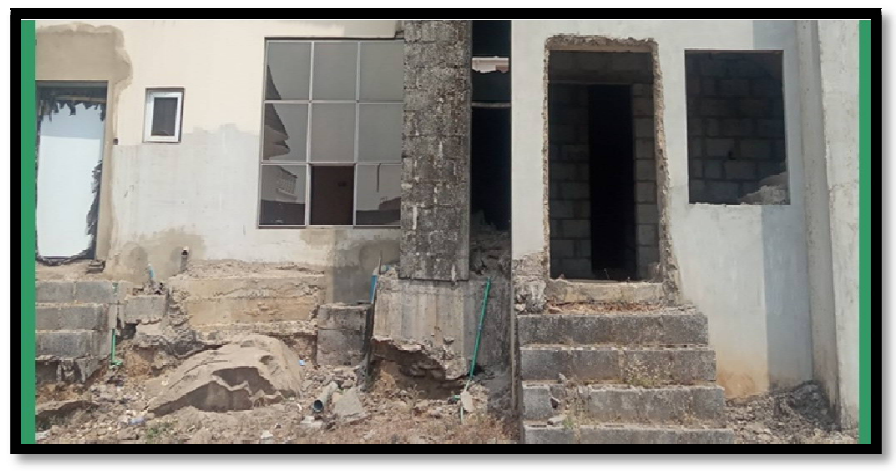

Figure 2: Footing Bases Composed of Loose Soil

Figure 3 below however depicted typical suspended floor cast on an uneven platform of formwork. The soffit of the hardened floor therefore assumed the uneven surface of the formwork. Similar abnormalities were witnessed in many places and these could attract serious increase in weight from possible plaster fill up. The use of thick plaster is obviously necessary in order to make even the soffits of the concrete floors. The increased thicknesses not only reduce headroom but also contribute to the weight of the floors with consequent rise in the overall weight of the structure. 


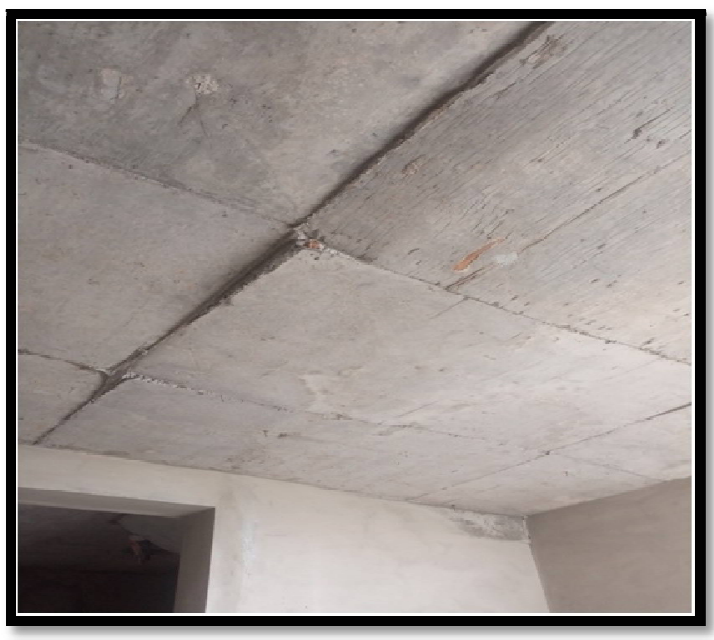

Figure 3: Soffit of Poorly Constructed Suspended Concrete Floor

Indeed, placing foundations on the surface of the ground or close to surface without digging proper trench could surely attract settlement especially where the ground is of vegetable soil nature. Another serious threat could be from lateral loading such as wind or storm forces. In fact, buildings or parts of the buildings whose foundations remain at surface or close to surface levels could entertain sway or complete uproot.

On the other hand, exceeding the design load of the building could upset the calculated structural status thereby posing failure threats. In reality, increase in member size means increase in load per unit length and this may require additional structural measures including the provision of more reinforcement bars; the absence of which could result to failure. In actual facts, the beams or other structural members initially designed to carry some specific loads could sag when the initial load is exceeded.

The appearance of several sagged members in the structure may not be unconnected with over loading. Even though, the individual member increase may be small, but the overall weight of all member increases when added which could pose serious menace to the established soil bearing capacity.

\subsection{Building Sway}

Building sway is definitely an eyesore to observers and more importantly scaring to occupants. A look from the tarred road passing in front of the 'Plot' in an axis parallel to the front side of the erected structure revealed some amount of sway particularly towards the end of the structure. It isn't surprising when the inventory team stumbled on what looks like cladding but using blocks, while in actual sense it is a way of making up a wall that has deviated from its bearing or real standing position. Figure 4 below presents increase in wall thickness using parts of locks.

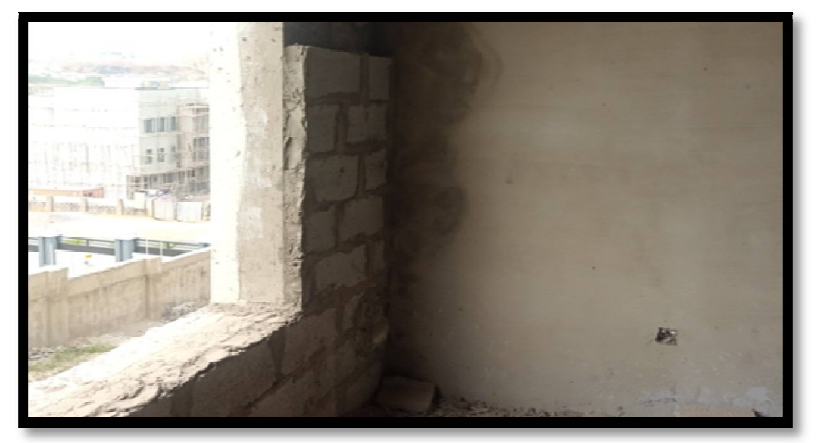

Figure 4: Increase in Wall Thickness through Cladding with Blocks

Buildings where human inhabits are absolutely intended to provide the desired comforts. Generally, where sway is perceived in a building, the desired comfort is lost due to eminent danger usually associated with sway. In many instances, dwellers residing in the neighbor-hood buildings adjacent to swayed structure hardly enjoy rest of mind until the affected structure is completely pulled down.

\subsection{Sagging}

It is to dismay of the inventory team that, there are many members in the structure which entertained some amount of sagging. The worst hit in this form of structural defect are window openings. Figure 5 below displays typical sagging at window opening where the precast lintel curved downwards. 


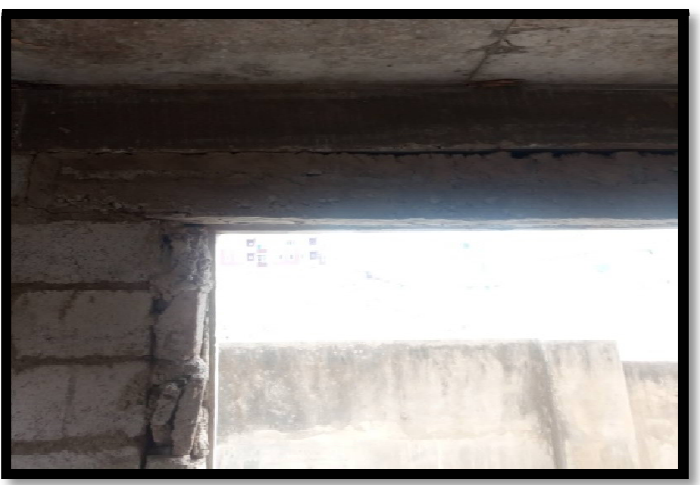

Figure 5: Sagging at Window Opening

Generally sagging demonstrates structural deficiency associated with the sagged member. Reasons leading to sagging could be (i) under reinforcement, (ii) use of inferior materials, (iii) construction of undersized member, (iv) poor workmanship, and (v) over loading. In this respect, it takes diligent and experience inventory experts to ascertain violation with regards to items (i) and (ii), evidently, items (iii), (iv) and (v) which were observed and confirmed.

Consequences of sagging in structural members in buildings include excessive downward pressure on windows and doors making creaking noise during opening, formation of cracks thereby aiding reinforcement corrosion due to ingress of moisture, member inability to effectively perform its intended designed function as well as partial or total collapse.

\subsection{Fear of Collapse}

Figure 6 below presents upper portion of the front elevation where two vertical white painted columns appeared on the left side and not on the right. Critical exploration confirmed the existence of similar columns on the right but abruptly removed most likely due to eminent danger of collapse. One could imagine all these happening without the interception by any of the regulatory and monitoring teams?

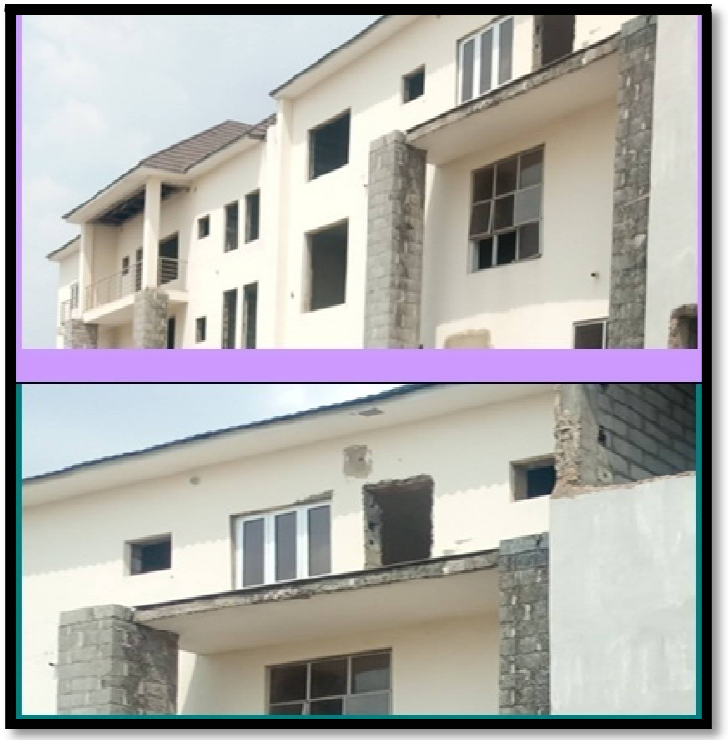

Figure 6: Removed Columns in Fear of Collapse

\subsection{External Works}

The external works which include provision of feasible premises with all the facilities needed for safe, healthy and pleasant living are not in focus. Currently, the premises as it contains an almost inaccessible vehicular entrance mainly due to a highly steep ramp which most cars cannot cross without possible damage to the front bumpers or silencers. Figure 7 portrays a portion of the entrance showing the gradient of the ramp in relation to the normal ground on the left side. This project is located right in the nation capital, but there is complete absence of the regulatory bodies, if they are regular or ever visit the site right from the commencement, this ill could have been addressed and could definitely not reach this magnitude. There is rather no significant piece of execution to show the presence and expertise of the regulatory bodies' and monitoring teams. This indeed had depicted the state of decay and gap in the industry services delivery waging for immediate tangential strategic actions if the future must be safeguard from further occurrence.

\section{Discussion \& Developing Executive Presence}

A psyche at the global context revealed china as the fastest builders by erection of 30 Storey building in 15 days at about 360 hours by the company Broad group. China academy of building research had tested to withstand $9 \mathrm{~mm}$ earthquake and five times more quake resistant than conventional buildings. In this decade concept homes with 10-15- 
year horizon showcased innovations in material and construction as attention turns from future gadgets to the science of buildings. Forum of construction industry leaders (2011) carried comparative evaluation of the construction industrial development initiatives in Hong Kong, Singapore and the UK with vision to be world class builders in this knowledge age. The strategic thrust was geared towards enhancing professionalism, raising skill levels, improving the industry practices and techniques, an integrated approach to construction and ... The outcome in Singapore led to a shift from a 3D (Dirty, Demanding and Dangerous) to 3P (Professional, Productive and Progressive) industrial culture.

From the analysis of the literature, the occurrence arisen from defective architectural engineering and building production failure in some instances. The difficulties arising from feasibility studies and subsequent required soil and site investigation which led in some chosen to transfer or rather amend previous work at the expense of a new design. With technology, and smart growth movement effectiveness and efficiency can be enhanced in all ramifications. The trouble of adjustment due to the uncertainty nature of client can be managed with BIM (building information modeling). The potential and relevance of big data Internet of things (IOT) cannot be over emphasized this era. The use of sub-standard materials, absence of building or planning permit, non-adherence to approved building plans are issues critical and key to sustainable development goals which can be curtailed. As digital technologies merge with unmanned aircraft system the drones'the issues of monitoring and enforcement shall be enhanced. The major failures are attributed to the regulatory bodies NIA, CORBON AND COREN. The world is moving towards smart society inference drawn from the study had shown that it's a collective failure by all in the profession. Greater part of the shortcoming is regulation, monitoring and enforcement. To put an end or rather minimize these if there will be empowerment by the government, embracing changing dynamics, technology 'big data and IOT (internet of things) 'the resource collaborations' to improve how the public sector works.

Considering the realities of times, a logical path and exit should be pursued to live in line with the professional ethics and the changing dynamics. In developed countries to improve agility and inter-operability, organizations resort to cloud computing survey for 24/7 data, to ensure effective monitoring and inspection on facilities. Bridging the divide between ineffectiveness and performance requires closing the gap between IT and agency operational process. The changing role of information technology no doubt drives collaboration and innovation, as cloud computing and mobility are driving public sector digital transformation. Critical information that informed decision is obtained through big data and IOT with Instant connectivity to deliver on expectations. This requires integrating people to data, machine and applications to meet specific objectives and goals of the organizations. The issues associated with development, agency and regulatory control are easily checked and monitored. Big data and IOT are challenged to connect more people, systems and devices than ever, paving way to a new world of business opportunities. Flexibility is indeed magnified supporting growing mobility with set of metrics to ensure monitoring and delivering rightly information to the right people, right location at right time. This will greatly enhance commitment of resources in all ramifications. While concluding this research piece on the 04/04/20 there was breaking news over the television of another collapse in Benue state this no doubt well informed the industry of the need to refocus with all might the radar in strategy reforms to make, better, effective and efficient regulations and enforcement by agency and corporate bodies.

The nation and profession should focus more than ever on eradicating quacks and minimizing the alarming building failures in Nigeria. To succeed in moving beyond this static up-front timeliness, in order to manage work integrated and dynamically big data and IOT is fundamental. The information system has to be flexible and accommodates certain amount of variability and requirements for the bodies and regulatory agency to be effective and efficient.

\section{Summary}

Many organizations are driving towards the path of innovation, moving from discrete and disparate systems to big data and IOT. As new technology emerges at exponential pace and security threats ever multiplying old strategies cannot longer yield the desire [19]. In developed countries Government data centres and internet migrate to public and private cloud in order to remain relevance [16]. This strategic effort and change in narratives require the agencies and corporate bodies' applications and security architecture to move beyond the hype onto the cloud to provide a better digital experience and efficiency. This is an integrated delivery system in the most appropriate settings rationalizing services delivery to next level 'the optimal'.

The emergence of BIM mandates and GIS integration, the digital innovation will bring solace, performance and excellence in the service delivery at the construction industry. While the big data and IOT avail vast opportunities and business value, it also presents significant challenges with security and environmental concern topmost. The future of optimizing buildings, infrastructures and increasing precision in decision making lies with the software definition (SD) which offers security with no borders (geography boundaries are erased). Artificial intelligence (AI) significantly enhanced and compliment technologies. This can be used for quality management investigation as many organizations are yielding to automation to compliment dangerous, variety and time-consuming tasks using robot. Such services include preventive maintenance, intelligent processing and IT automation. As recommendation this area can be further explore to magnify effectiveness and efficiency in regulation, monitoring and enforcement. Citizen expectation are changing, demanding faster and more creative solutions and services, AI as compliment and the logical option to deliver effectively the future.

\section{References}

i. Architect \& Urbanism (2012). Singapore Capital city for Vertical Green 'Special Edition'

ii. Umbugala, M. D. (2017). Best practices in building construction: A psyche and benchmark of selected few countries and Nigeria' Environmental Planning and Sustainability Vol. 1/1 pp 107-125.

iii. e republic.com (2020): Marketing 
iv. Umbugala M. D \& Hishamuddin B M A (2019). Delivery an Effective Workplace 'A Search into Malaysian Firms' Business \& Management Vol. 7/2, pp 51-58.

v. Umbugala, M. D. (2009). Timeless Practice framework, as facilities management Outsourcing performance evaluation model. Thesis submitted in fulfilment for the award PhD, Doctor of philosophy (facilities management) at Universiti Teknologi Malaysia.

vi. Chendo I G \& Obi N. I (2015): Building Collapse in Nigeria the causes-effect, Journal of civil engineering, construction and estate management Vol 3 / 4, pp.41-49Daily Times April, 2013

vii. $\quad$ Nigerian Building \& Road Research Institute (NBBR1)

viii. Adebowale P A., Gambo M D., Ankeli I A., Dabara D I (2016). Building Collapse in Nigeria 'Issues and Challenges' Arts \& Sciences 09/1 pp 99-108.

ix. [Adeyemi S. O, Z T Giwa\& R. Abdulwahab (2019). Building collapse in Nigeria (2009-2019), causes and remediesA review. https//www.Researchgate.net

x. Guardian Newspaper March 2016 'https//gaudian.ng/building collapse'

xi. www.nascio.org 'survey'

xii. www.public.cio.com

xiii. www.centredigitalgov.com

xiv. e.Republic, (2019) 'Smart Media for Public Sector Innovation'

xv. Beyond the Hype' A guide for the intelligence use of Artificial Intelligence (AI)

xvi. Digital Communities (2020): Newsletter@govtech.com

xvii. Punch Jan, 27th (2020): Nigeria recorded 43 building collapse in 2019 Report

xviii. Umbugala, M. D. (2016). Finding the niche towards performance excellence 'A study of facilities management firms in Malaysia' Facilities Management, 14(4). 